\title{
Potential of Bacterial Cellulose Chemisorbed with Anti-Metabolites, 3-Bromopyruvate or Sertraline, to Fight against Helicobacter pylori Lawn Biofilm
}

\author{
Paweł Krzyżek ${ }^{1, *(1)}$, Grażyna Gościniak ${ }^{1}{ }^{(0)}$, Karol Fijałkowski ${ }^{2}{ }^{(0}$, Paweł Migdał ${ }^{3}{ }^{(0}$, \\ Mariusz Dziadas ${ }^{4}{ }^{\oplus}$, Artur Owczarek ${ }^{5}{ }^{\circledR}$, Joanna Czajkowska ${ }^{6}$, Olga Aniołek ${ }^{7}$ and \\ Adam Junka ${ }^{8}$ (i) \\ 1 Department of Microbiology, Faculty of Medicine, Wroclaw Medical University, 50-368 Wroclaw, Poland; \\ grazyna.gosciniak@umed.wroc.pl \\ 2 Department of Immunology, Microbiology and Physiological Chemistry, Faculty of Biotechnology and \\ Animal Husbandry, West Pomeranian University of Technology in Szczecin, 70-311 Szczecin, Poland; \\ karol.fijalkowski@zut.edu.pl \\ 3 Department of Environment, Hygiene and Animal Welfare, Wroclaw University of Environmental and Life \\ Sciences, 51-630 Wroclaw, Poland; pawel.migdal@upwr.edu.pl \\ 4 Faculty of Chemistry, University of Wroclaw, 50-353 Wroclaw, Poland; mariuszdziadas@gmail.com \\ 5 Department of Drug Form Technology, Wroclaw Medical University, 50-556 Wroclaw, Poland; \\ artur.owczarek@umed.wroc.pl \\ 6 Laboratory of Microbiology, Polish Center for Technology Development PORT, 54-066 Wroclaw, Poland; \\ czajkowskaj@hotmail.com \\ 7 Faculty of Medicine, Lazarski University, 02-662 Warsaw, Poland; olga.aniolek@lazarski.pl \\ 8 Department of Pharmaceutical Microbiology and Parasitology, Wroclaw Medical University, \\ 50-556 Wroclaw, Poland; feliks.junka@gmail.com \\ * Correspondence: krojcerpawel@gmail.com
}

Received: 23 November 2020; Accepted: 11 December 2020; Published: 14 December 2020

\begin{abstract}
Helicobacter pylori is a bacterium known mainly of its ability to cause persistent inflammations of the human stomach, resulting in peptic ulcer diseases and gastric cancers. Continuous exposure of this bacterium to antibiotics has resulted in high detection of multidrug-resistant strains and difficulties in obtaining a therapeutic effect. The purpose of the present study was to determine the usability of bacterial cellulose (BC) chemisorbed with 3-bromopyruvate (3-BP) or sertraline (SER) to act against lawn H. pylori biofilms. The characterization of $\mathrm{BC}$ carriers was made using a N2 adsorption/desorption analysis, tensile strength test, and scanning electron microscopy (SEM) observations. Determination of an antimicrobial activity was performed using a modified disk-diffusion method and a self-designed method of testing antibacterial activity against biofilm microbial forms. In addition, bacterial morphology was checked by SEM. It was found that BC disks were characterized by a high cross-linking and shear/stretch resistance. Growth inhibition zones for BC disks chemisorbed with $2 \mathrm{mg}$ of SER or 3-BP were equal to $26.5-27.5 \mathrm{~mm}$ and $27-30 \mathrm{~mm}$, respectively. The viability of lawn biofilm $H$. pylori cells after a 4-h incubation with $2 \mathrm{mg}$ SER or 3-BP chemisorbed on BC disks was $\geq 4 \log$ lower, suggesting their antibacterial effect. SEM observations showed a number of morphostructural changes in H. pylori cells exposed to these substances. Concluding, SER and 3-BP chemisorbed on $\mathrm{BC}$ carriers presented a promising antibacterial activity against biofilm $\mathrm{H}$. pylori cells in in vitro conditions.
\end{abstract}

Keywords: Helicobacter pylori; bacterial cellulose; anti-biofilm activity; morphology; 3-bromopyruvate; sertraline 


\section{Introduction}

Helicobacter pylori of Epsilonproteobacteria class is a Gram-negative bacterium known primarily of its ability to cause persistent inflammation of the human stomach, resulting in such pathological alterations as peptic ulcer diseases, gastric cancers, and mucosa-associated lymphoid tissue lymphomas [1,2]. H. pylori colonizes and survives in the harsh environment of stomach thanks to the number of adaptations, which include spiral shape, urease secretion, and adhesin-mediated adherence to mucosa [3]. The variety and maliciousness of $H$. pylori virulence factors was the reason why the latest Maastricht $\mathrm{V}$ guidelines recommend to eradicate this bacterium, even if disease symptoms have not yet appeared [4].

Currently, antibiotics still remain the only acceptable treatment option against H. pylori. Regrettably, continuous exposure of $\mathrm{H}$. pylori to these antimicrobials has resulted in alarmingly high detection of multidrug-resistant (MDR) strains [5]. The issue of aforementioned pathogens' antibiotic resistance is an important and current topic [6]. The prevalence of antibiotic-resistant strains is considered so high that $\mathrm{WHO}$ has placed H. pylori on the list of pathogens whose treatment requires the development of new eradication standards [7]. Due to a lack of new solutions, a bismuth quadruple therapy (BQT) is presently recommended as a first line of treatment [8]. This therapy has a satisfactory level of approximately $90 \%$ eradication [9-11]. For the currently recommended BQT, however, a negative effect on patients' microbiota has been demonstrated [12-15]. Additionally, the systemic BQT, despite its relatively good tolerance, contributes to the occurrence of side effects in patients, which in consequence may affect non-adherence and therapeutic failures [16]. Taking into account above-mentioned disadvantages of BQT and high adaptability of $H$. pylori, an implementation of novel, efficient anti- $H$. pylori compounds is of paramount importance [6].

There are two promising compounds, namely 3-bromopyruvate (3-BP) and sertraline (SER), for which an antimicrobial activity against planktonic and biofilm forms of different pathogens was demonstrated [17-21]. Both of them affect a number of targets in microbial cells, including protein synthesis, metabolic pathways, and production of intracellular ATP. Therefore, these substances are often referred to as anti-metabolites. Our team has already demonstrated not only the antibacterial activity of 3-BP and SER against planktonic $H$. pylori cells, but also synergistic/additive interactions of these compounds with antibiotics, providing proof of the concept for their future clinical application as adjuvants of these antimicrobials [22,23]. Despite the fact that pharmacological parameters and the level of cytotoxicity make the use of 3-BP and SER in a systemic therapy possible [24,25], this route of drug administration is frequently associated with such disadvantages as low bioavailability, limited penetration into affected tissues, and an induction of resistance among human microbiome representatives [26].

We hypothesize that 3-BP and SER should be provided to gastric mucosa, disturbed by the ongoing H. pylori colonization/infection, by a local administration. Such approach requires coupling of antimicrobial substances with an appropriate carrier, in order to provide them to the infection site. There is a number of carriers which could be possibly used for the delivery of these compounds, including liposomes, microspheres, nanoparticles, and a variety of polymeric carriers of artificial or natural origin [26-28]. In our opinion, bacterial cellulose (BC) produced by non-pathogenic Komagataeibacter xylinus is the most suitable among them, due to broad spectrum of favorable physical and chemical properties [26-28]. Compared to plant cellulose, BC of microbial origin has a higher degree of crystallization and polymerization, which translates into a higher absorption capacity. Therefore, it displays a very high ability to absorb and release drugs from within its porous structure. Moreover, it exhibits a high mechanical strength (resistance to shear) and a high elastic modulus (an ability to retain shape after stretching) [29]. Moreover, BC's chemical composition is identical with composition of plant cellulose and is not digested in harsh environment of stomach [30]. Our team has already shown the suitability of BC chemisorbed with antibiotics and antiseptics to fight against biofilms formed by pathogens responsible for infections of wounds [31], bones [32-34], and oral cavity [35]. 
Therefore, the purpose of the present study was to determine the usability of $\mathrm{BC}$ chemisorbed with 3-BP and SER to act against biofilm of $H$. pylori.

\section{Materials and Methods}

\subsection{Culture Conditions and Bacterial Strains Used}

The research was carried out using two selected H. pylori strains, i.e., antibiotic-sensitive, reference Tx30a (ATCC 51932) stain from the American Type Culture Collection (ATCC) and triple-resistant, clinical 8064 strain (resistant to clarithromycin, metronidazole, and levofloxacin) belonging to the collection of the Department of Microbiology, Wroclaw Medical University. An antibiotic resistance profile has been established using E-tests and interpreted according to EUCAST (2019) recommendations [36]. Strains of $H$. pylori were kept at $-70{ }^{\circ} \mathrm{C}$ in Tryptic Soy Broth (TSB; Oxoid, Dardilly, France) and 15\% glycerol [22,23]. After thawing, bacteria were cultured on Columbia agars (Difco, Lublin, Poland) with 7\% hemolyzed horse blood (CA+HB). Plates with seeded bacteria were directed to a 3-day incubation under microaerophilic conditions (Genbox microaer kits, BioMerieux, Marcy-l'Étoile, France) at $37^{\circ} \mathrm{C}$.

\subsection{Carrier Characteristics}

In order to obtain BC membranes of the same diameter, stationary culture of Komagataeibacter xylinus DSM 46602 were grown in the Herstin-Schramm medium in a 24-well plate (Nest Biotechnology Co., Wuxi, China) for 7 days at $28^{\circ} \mathrm{C}$. The $\mathrm{BC}$ pellicles harvested from the medium were next purified by alkaline lysis, washed with distilled water, autoclaved, and kept in $4{ }^{\circ} \mathrm{C}$ for the time of further analyses.

To determine the wet and dry weight of the samples, $\mathrm{BC}$ pellicles were weighed using an analytical balance and then dried at $60^{\circ} \mathrm{C}$ overnight and weighed again (WTB 2000 Radwag, Radom, Poland). The microstructure of the BC membrane was analyzed using SEM (Auriga 60, Zeiss, Jena, Germany). $\mathrm{BC}$ membranes were fixed in glutaraldehyde ( $\mathrm{POCH}$, Gliwice, Poland) and subjected to the sputtering with $\mathrm{Au} / \mathrm{Pd}$ (60:40) using a high vacuum coater (EM ACE600, Leicasputter, Leica Microsystems, Wetzlar, Germany). The porosity of BC surface was analyzed by means of Image software (NIH, Bethesda, Rockville, MA, USA). The $\mathrm{N}_{2}$ adsorption/desorption isotherms at $77 \mathrm{~K}$ were measured using a Micromeritics ASAP 2010 M instrument (Micromeritics, Norcross, GA, USA) and the specific surface area was calculated by the Brunauer-Emmett-Teller method. The pore volume and pore diameter of whole sample were calculated by the Barrett-Joyner-Halenda method. The BC dressings' tensile strength test was performed using an MTS Synergie $100^{\circledR}$ machine (MTS System Corp, Eden Praire, MN, USA). The tests were carried out at a speed of $10 \mathrm{~mm} / \mathrm{min}$ at room temperature. Based on the recorded values of force and displacement, stress-strain graphs were prepared; and based on these graphs, mechanical parameters (such as tensile strength) were determined. Moreover, to determine an impact of low $\mathrm{pH}$ on $\mathrm{BC}$, samples were introduced to $5 \mathrm{M}$ and $10 \mathrm{M} \mathrm{HCl}$ (Poch, Wrocław, Polska) for $4 \mathrm{~h}$. The $\mathrm{BC}$ incubated in $0.9 \% \mathrm{NaCl}$ solution for $4 \mathrm{~h}$ served as control samples. After incubation, samples were taken out of solutions and analyzed visually with regard to their shape and color.

Additionally, the release rate of two tested substances (SER and 3-BP) using spectrometry was also determined. SER-chemisorbed BC carriers were placed in glass vessels containing $10 \mathrm{~mL}$ of a mixture methanol:water $(50: 50 \mathrm{v} / \mathrm{v})$ serving as the drug release medium. The absorbance of SER solutions was measured at $273 \mathrm{~nm}$ (Thermo Scientific Multiscan GO spectrometer). Analysis of 3-BP was performed on a model 1260 HPLC-UV/VIS system (Agilent, Santa Clara, CA, USA) on a Zorbax SB-C8 chromatography column, $80 \times 4.6 \mathrm{~mm}, 5 \mu \mathrm{m}$ (Grom, Germany). During this process a flow rate of $1 \mathrm{~mL} / \mathrm{min}$ in isocratic conditions using water:acetonitrile:phosphoric acid (9:1:0.1 v/v) was applied. The results were integrated and analyzed with the Chemstation B.04 software (Agilent, USA). 


\subsection{Determination of Antimicrobial Activity of Tested Compounds}

A microdilution method in 12-well titration plates (Bionovo, Legnica, Poland) was used to estimate minimal inhibitory concentrations (MICs) and minimal bactericidal concentrations (MBCs) for the two tested $H$. pylori strains [22,23]. The $1 \mathrm{~mL}$ of suspension was prepared in each well by diluting tenfold an initial bacterial suspension $\left(10^{8} \mathrm{CFU} / \mathrm{mL}, 4 \mathrm{McF}\right.$ arland units) in Brain Heart Infusion broth (BHI; Oxoid, Dardilly, France) with 7\% foetal calf serum (FCS; Gibco, Paisley, Scotland, UK) (BHI+FCS), thus resulting in the density of $10^{7} \mathrm{CFU} / \mathrm{mL}$. In addition, each well contained a concentration gradient of one of the tested compounds, i.e., SER (0.25-16 $\mu \mathrm{g} / \mathrm{mL}$, Sigma-Aldrich, St. Louis, MO, USA), 3-BP (8-512 $\mu \mathrm{g} / \mathrm{mL}$, Sigma-Aldrich), bismuth subsalicylate (BIS, $0.5-32 \mu \mathrm{g} / \mathrm{mL}$, Sigma-Aldrich), and amoxicillin (AMX, $0.015-0.96 \mu \mathrm{g} / \mathrm{mL}$, Sigma-Aldrich). Subsequently, plates containing bacteria were incubated at $37^{\circ} \mathrm{C}$ per 3 days in microaerophilic conditions and provided rotation of $100 \mathrm{rpm}$ (MaxQ 6000, ThermoFisher, Waltham, MA, USA).

The activity of SER or 3-BP released from BC carriers was determined by a modified diffusion-disk method as previously described $[33,37]$. The paper disks chemisorbed with the tested compounds were applied as a control setting of the experiment. In the case of AMX, ready-made paper disks were used ( $25 \mu \mathrm{g} / \mathrm{mL}$ Oxoid, France). The tested compounds were initially dissolved in DMSO (Sigma-Aldrich) and then diluted in BHI broths to obtain the final DMSO concentration $\leq 1 \%$. The paper and BC disks chemisorbed with BIS or AMX and 1\% DMSO solution served as a positive and negative controls of experiments, respectively. One centrally located cellulose disk $(15 \mathrm{~mm})$ or three evenly spaced paper disks $\left(6 \mathrm{~mm}\right.$ ) were placed on $\mathrm{CA}+\mathrm{HB}$ plates containing a lawn of bacteria (approx. $5 \times 10^{6} \mathrm{CFU} / \mathrm{mL}$ ). Culture media with sown bacteria and with applied disks (0.2, 1 and $2 \mathrm{mg}$ for SER, 3-BP and BIS, or $25 \mu \mathrm{g}$ for AMX per disk) were incubated under microaerophilic conditions at $37^{\circ} \mathrm{C}$ for 3 days. Additionally, the morphology of antimicrobial-treated H. pylori was determined by directing agar fragments from the area with a bacterial lawn (a positive control) and inhibited growth for a scanning electron microscopy (SEM) imaging.

To determine the activity of $\mathrm{BC}$ disks impregnated with the tested substances, a methodology established by Krasowski and Junka et al. (2019) [35] was used (Figure 1). The $2 \mathrm{~mL}$ of BHI agar (Oxoid, France) was added into each well of a 12-well titration plate and allowed to solidify for a one day. Then, $10 \mathrm{~mm}^{2}$ agar fragments were cut out from each well. Following this, $5 \mathrm{~mm}^{2}$ fragments of CA+HB agar with a three-day lawn $H$. pylori biofilms were placed in the empty space of each well (the lawn biofilms growth was done according to Dusane et al. (2019) and Lochab et al. $(2020)[38,39]$, with an incubation at $37^{\circ} \mathrm{C}$ and microaerophilic atmosphere). After this stage, the wells were filled with approx. $0.25 \mathrm{~mL}$ of BHI+FCS to obtain a convex meniscus. Finally, each well was covered from above with a $\mathrm{BC}$ disk containing $0.2,1$, or $2 \mathrm{mg}$ of the tested compounds (SER or 3-BP). The positive and negative control were disks with BIS or AMX and disks non-impregnated with any substance, respectively. Such bacteria were then cultured for $1-4 \mathrm{~h}$ at $37^{\circ} \mathrm{C}$, microaerophilic conditions, and $100 \mathrm{rpm}$ shaking.

The viability of $H$. pylori strains was determined by plating antimicrobial-treated bacteria and counting an amount of grown colonies. Agar fragments containing bacteria were mechanically crushed in $1 \mathrm{~mL}$ of BHI+FCS (homogenization according to Cooke et al. (2019) [40]). The resulting suspension was then serially diluted $\left(10^{1}-10^{3}\right)$ and $20 \mu \mathrm{L}$ of fluid was plated on $\mathrm{CA}+\mathrm{HB}$ agars. Such plates were incubated for 3 and 7 days under microaerophilic conditions and at $37^{\circ} \mathrm{C}$, and the number of grown colonies was counted independently for each time point. The viability was confirmed independently by using BacLight Live/Dead staining (L7012, ThermoFisher, USA) and fluorescence microscopy (Olympus BX51, Japan). Using the ImageJ program, determination of the green/red fluorescence ratio was made in relation to five regions of interests from three photos obtained from separate tests [22,23]. The morphology of antimicrobial-treated bacteria was determined by directing the agar fragments with bacteria for SEM [22,23]. The agar fragments were immersed in $0.2 \mathrm{~mL}$ of $2.5 \%$ glutaraldehyde (Sigma-Aldrich), washed two times with phosphate buffer (Sigma-Aldrich), and passed through an ethanol series. Such samples were dried at room temperature, sprayed with $15 \mathrm{~nm}$ of gold, and observed using SEM (Auriga 60, Zeiss, Germany). 

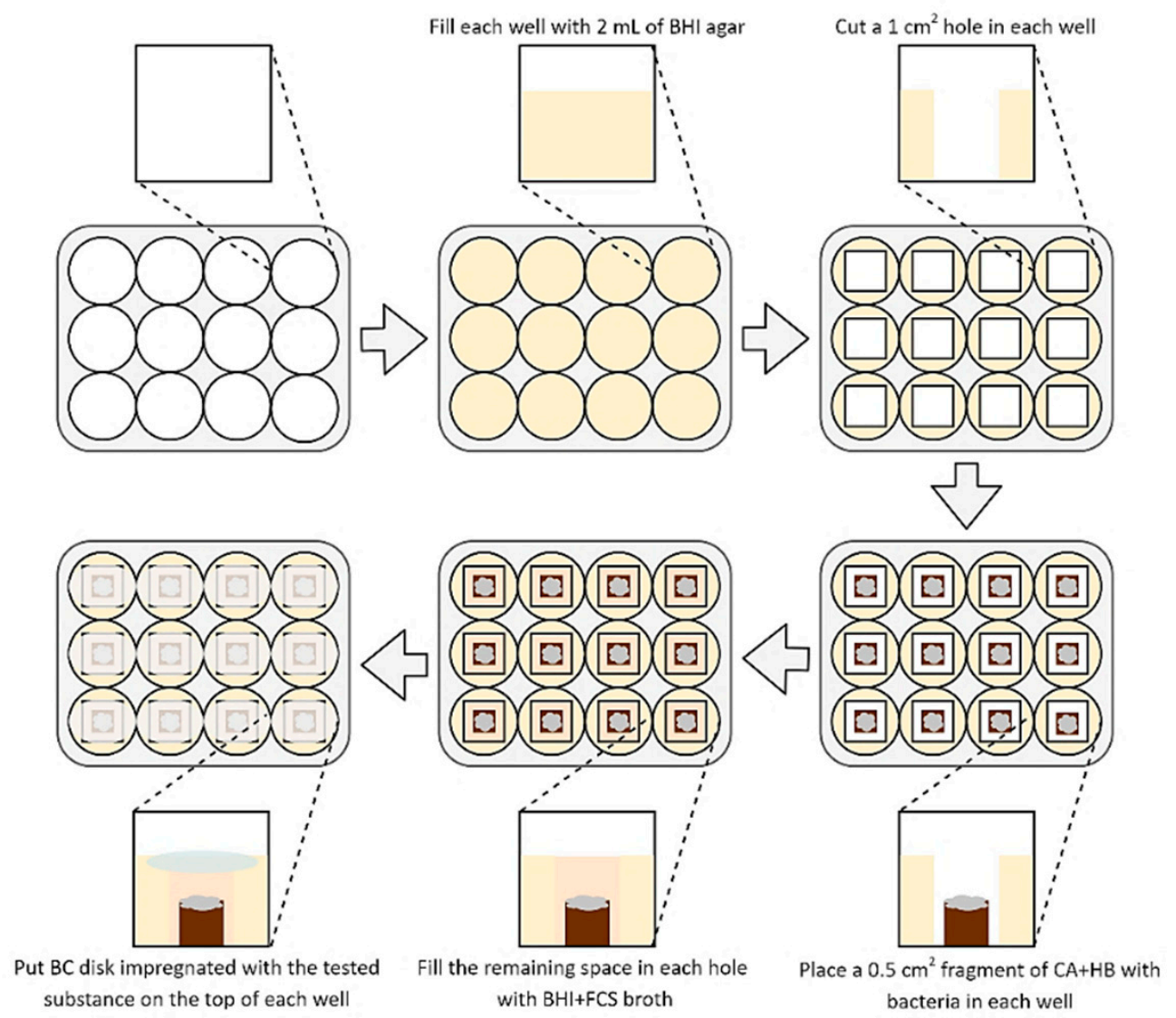

Figure 1. Diagram presenting a method used to determine an antimicrobial activity of tested substances released from $\mathrm{BC}$ carriers against 3-day lawn biofilm $H$. pylori cells. Abbreviations: $\mathrm{BHI}$ agar, Brain Heart Infusion agar; BHI+FCS broth, Brain Heart Infusion broth with 7\% foetal calf serum; CA+HB, Columbia agar with $7 \%$ hemolysed horse blood.

\subsection{Statistical Analysis}

Statistical differences were assessed using the Kruskal-Wallis test with a post-hoc Dunnett's analysis. Data is presented as the means \pm standard errors of the means (SEM) obtained from three different measurements (+technical repeats). All analyses were considered statistically significant when the $p$ value was less than 0.05 .

\section{Results}

In the first line of experiments, we applied a standard titration plate assessment of MICs and MBCs to confirm whether 3-BP and SER display an antimicrobial activity against the tested H. pylori strains. In the same setting, also BIS and AMX were used as substances of already confirmed activity against $H$. pylori. The highest antibacterial activity was demonstrated for AMX with MICs ranging from $0.06-0.12 \mu \mathrm{g} / \mathrm{mL}$. We found that the multidrug resistant $H$. pylori 8064 (resistant to clarithromycin, metronidazole, and levofloxacin) was more sensitive to AMX (MIC $=0.06 \mu \mathrm{g} / \mathrm{mL}$ and $\mathrm{MBC}=0.12 \mu \mathrm{g} / \mathrm{mL}$ ) than the antibiotic-sensitive H. pylori $\mathrm{T} \times 30 \mathrm{a}(\mathrm{MIC}=0.12 \mu \mathrm{g} / \mathrm{mL}$ and $\mathrm{MBC}=$ $0.48 \mu \mathrm{g} / \mathrm{mL}$ ). This is consistent with the observations of others showing that antibiotic resistance in H. pylori is associated with point mutations in drugs' targets and their presence results in insensitivity to a given group of antibiotics, but does not translate into resistance to other antibiotics [41,42]. Additionally, it is worth mentioning that with regard to the antimicrobial activity, SER had relatively comparable properties to BIS ( $2-4 \mu \mathrm{g} / \mathrm{mL}$ and $2 \mu \mathrm{g} / \mathrm{mL}$, respectively) (Table 1 ). The 3-BP, although also able to act against $H$. pylori, had MIC at the level of a dozen times higher than the two substances mentioned earlier $(128 \mu \mathrm{g} / \mathrm{mL})$ (Table 1$)$. 
Table 1. MICs and MBCs of amoxicillin (AMX), bismuth subsalicylate (BIS), sertraline (SER), and 3-bromopyruvate (3-BP) against H. pylori Tx30a and 8064 strains.

\begin{tabular}{ccccccccc}
\hline \multirow{2}{*}{ H. pylori Strains } & \multicolumn{2}{c}{ SER } & \multicolumn{2}{c}{ 3-BP } & \multicolumn{2}{c}{ AMX } & \multicolumn{2}{c}{ BIS } \\
\cline { 2 - 9 } & MIC & MBC & MIC & MBC & MIC & MBC & MIC & MBC \\
\hline Tx30a & 4 & 8 & 128 & 128 & 0.12 & 0.48 & 2 & 2 \\
8064 & 2 & 2 & 128 & 128 & 0.06 & 0.12 & 2 & 4 \\
\hline
\end{tabular}

MICs and MBCs are expressed as $[\mu \mathrm{g} / \mathrm{mL}]$.

Having the ability of the tested compounds to act against $H$. pylori proven, we characterized the most crucial properties of $\mathrm{BC}$ as drug carriers. Because all BC carriers were cultured and purified within single production process, their parameters were of high consistency and comparability between particular disks. The diameter of $\mathrm{BC}$ carriers was $1.5 \mathrm{~cm}$ and its average wet and dry weight was equal to $0.5 \mathrm{~g}$ and $0.004 \mathrm{~g}$, respectively. SEM analysis of a BC microstructure revealed pore-forming 3-D network of intertwined cellulose fibers (Figure 2). By means of a post-SEM image processing, the porosity of BC surface was established on $92 \pm 126 \mathrm{~nm}$, averagely. Using N2 adsorption/desorption analysis, we showed that $\mathrm{BC}$ carriers displayed average surface area of $9.37 \pm 0.28 \mathrm{~m}^{2} / \mathrm{g}$, average pore volume of $0.026 \pm 0.007 \mathrm{~cm}^{3} / \mathrm{g}$, and average pore diameter of $3.01 \pm 0.18 \mathrm{~nm}$. Another key parameter of a carrier to be applied in the harsh environment of stomach is mechanical strength (resistance to shear). Analysis we performed revealed that obtained BC carriers displayed the average tensile strength of $4.27 \pm 0.77 \mathrm{MPa}$ and average Young's modulus equal $11.79 \pm 1.05 \mathrm{MPa}$. Moreover, BC was resistant to digestion in in highly acidic conditions $(\mathrm{pH}<2)$ during $4 \mathrm{~h}$ of incubation (Supplementary Figure S1).
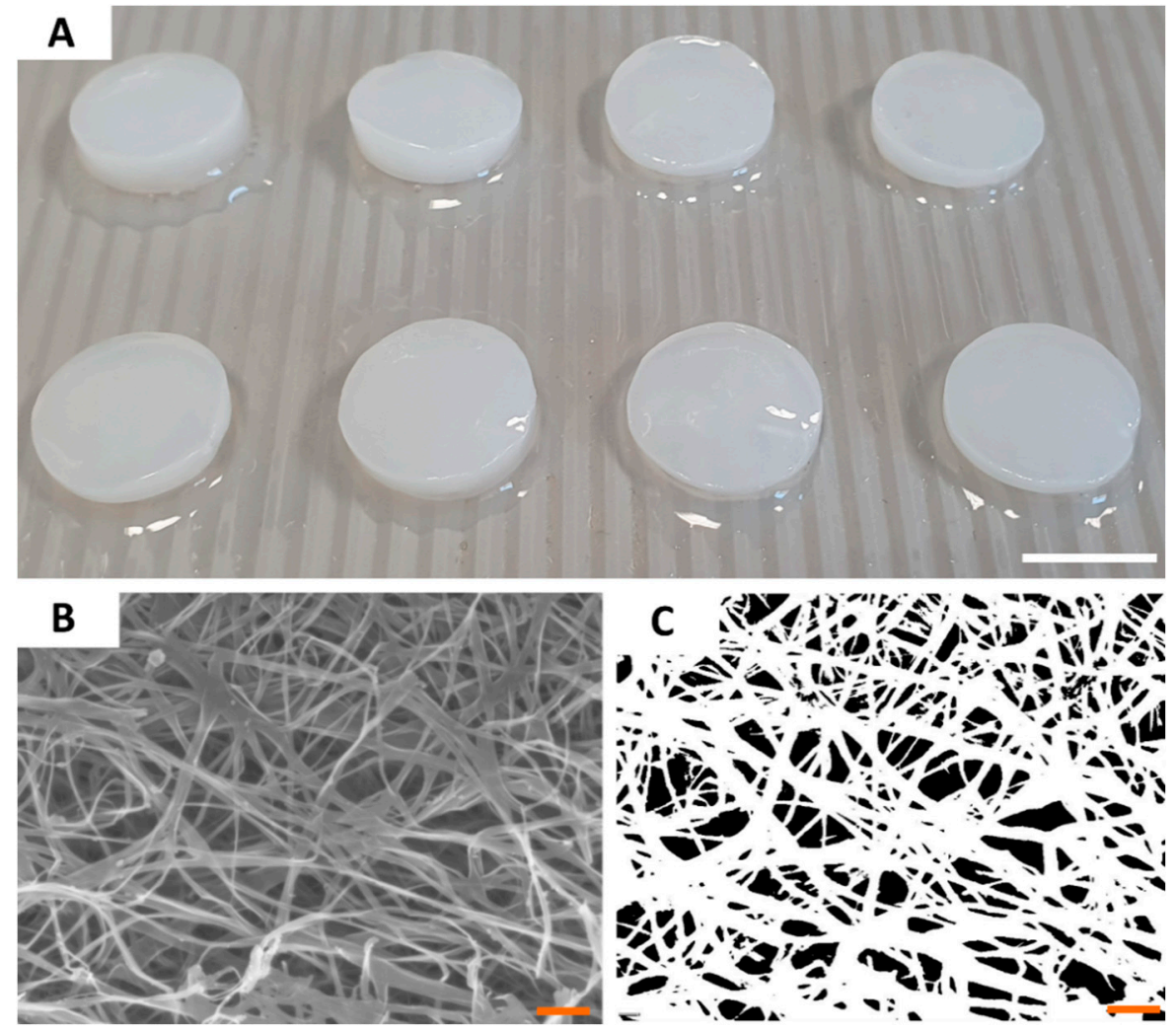

Figure 2. The macroscopic (A) and microscopic $(\mathbf{B}, \mathbf{C})$ pictures of $B C$ carriers. The picture $(\mathbf{B})$ was taken using SEM Auriga 60 microscope under magnification equal 50,000x; and subjected to re-processing (C) which allowed to calculate the porosity of carrier surface. Scale bars are equal to $1 \mathrm{~cm}$ in photo (A) and $1 \mu \mathrm{m}$ in photos $(\mathbf{B}, \mathbf{C})$. 
After the stage of characterization of BC carriers, we chemisorbed them with the tested compounds. Using spectrometry, we observed that after $1 \mathrm{~h} \sim 31 \%$ and $\sim 42 \%$ of SER and 3-BP, respectively, was released from BC disks. A prolonged incubation did not increase significantly the amount of resorbed compounds (Supplementary Figures S2 and S3). Obtained results confirmed the ability of BC carriers to chemisorb SER and 3-BP. Therefore, in our next line of investigation we analyzed their activity against $H$. pylori strains using a modified disk-diffusion method. As it can be seen in Figure 3, the novel 3-BP and SER compounds displayed equal (e.g., $1 \mathrm{mg}$ and $2 \mathrm{mg}$ for H. pylori Tx30a, $p>0.05$ ) or higher ( $2 \mathrm{mg}$ for H. pylori 8064, $p<0.05$ ) activity against the tested H. pylori strains in comparison to BIS. Among the tested compounds, even despite its low dose of $25 \mu \mathrm{g}$, AMX had the highest activity $(p<0.05)$. In addition, it was noticed that unlike non-treated bacteria (a bacterial lawn area) being a mixed population of spiral and coccoid forms, the cells in zones of inhibited growth were only in the spherical form (Figure 3). The data concerning control settings, where paper disks chemisorbed with the tested substances, were applied as presented in Supplementary Figure S4.

Next, the activity of tested compounds was assessed by a self-designed method of testing antibacterial activity against lawn biofilms (Krasowski, Junka et al., 2019) [35] (Figure 1). In this experimental model, it was observed that survival of the H. pylori strains was negatively correlated with the time of exposure to BC chemisorbed with antimicrobials and their concentrations (Figure 4 and Supplementary Figure S4). Moreover, it was discovered that SER and 3-BP showed a higher activity against 3-day-old lawn $H$. pylori biofilms than BIS or AMX $(p<0.05)$. It is worth to notice that in comparison to the control samples, a 4-h incubation with all tested compounds decreased the viability of lawn $H$. pylori biofilms significantly $(p<0.05)$.

Above-presented results were additionally confirmed by microscopy. Fluorescence microscopy showed a decrease in the amount of live, biofilm $H$. pylori cells upon exposure to 3-BP and SER released from BC carriers $(p<0.05)$. For example, compared with untreated cells mean green/red fluorescence was 7- and 15-fold lower in biofilm H. pylori cells exposed to 3-BP and SER, respectively. Surprisingly, exposure of these bacteria to AMX had a low impact on the viability of biofilm cells ( $p>0.05$, Figure 5). To broaden the picture of the phenomenon, the analysis was extended by SEM (Figure 5). It was observed that $H$. pylori, placed on solid agars and immersed in liquid medium, formed highly complex aggregates consisted of numerous rod-shape cells (a positive control). Moreover, an existence of single small outer membrane vesicles (mostly OMVs of approx. $50 \mathrm{~nm}$ ) was observed. After exposure on BIS, H. pylori still maintained mainly its rod-like morphology, although some cells transformed into coccoid forms. Cells of H. pylori treated with SER, 3-BP or AMX were present in the spherical morphotype only. Furthermore, numerous OMVs covering bacteria (mainly with 100-300 nm diameters) and the existence of intercellular junctions taking the shape of short or very long fibrils (particularly intensely visible for SER-treated cells) were noticed. 

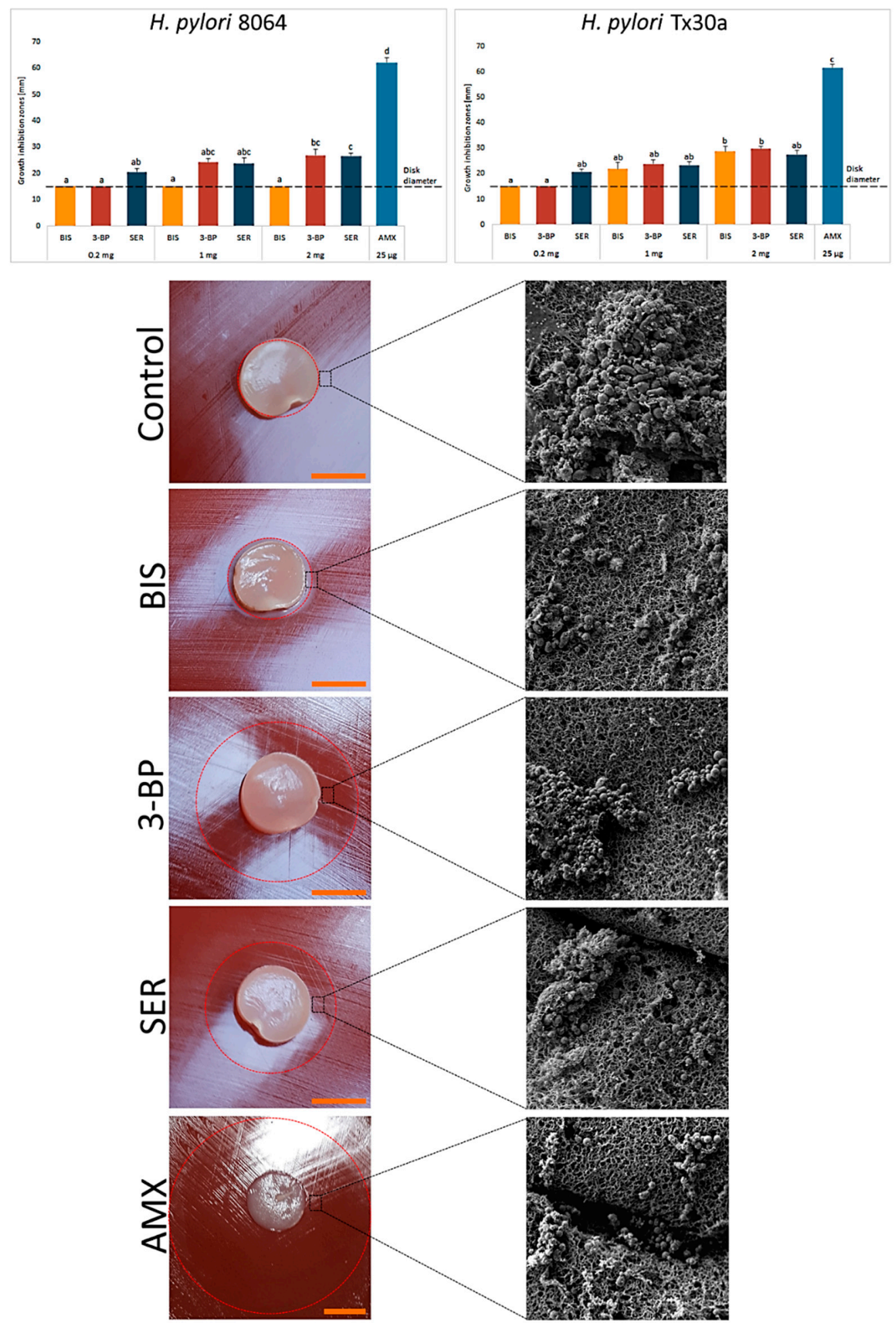

Figure 3. Activity of bismuth subsalicylate (BIS), 3-bromopyruvate (3-BP), sertraline (SER), and amoxicillin (AMX) released from BC carriers against H. pylori 8064 and Tx30a strains measured by a modified disk-diffusion method. Asterisks stand for a statistical significance (K-W test with post-hoc Dunn's analysis). The dot-line at the value of $15 \mathrm{~mm}$ represents the diameter of BC carrier. Representative photos of $H$. pylori 8064 growth inhibition zones and cell morphology after exposure to BC carriers not chemisorbed (a negative control) or the tested compounds. Columns with the same subscript letters $(a, b, c)$ are not significantly different from each other $(p>0.05)$. The presented results are the average of three independent biological tests $(n=3)$. Scale bar is equal to $1 \mathrm{~cm}$. 


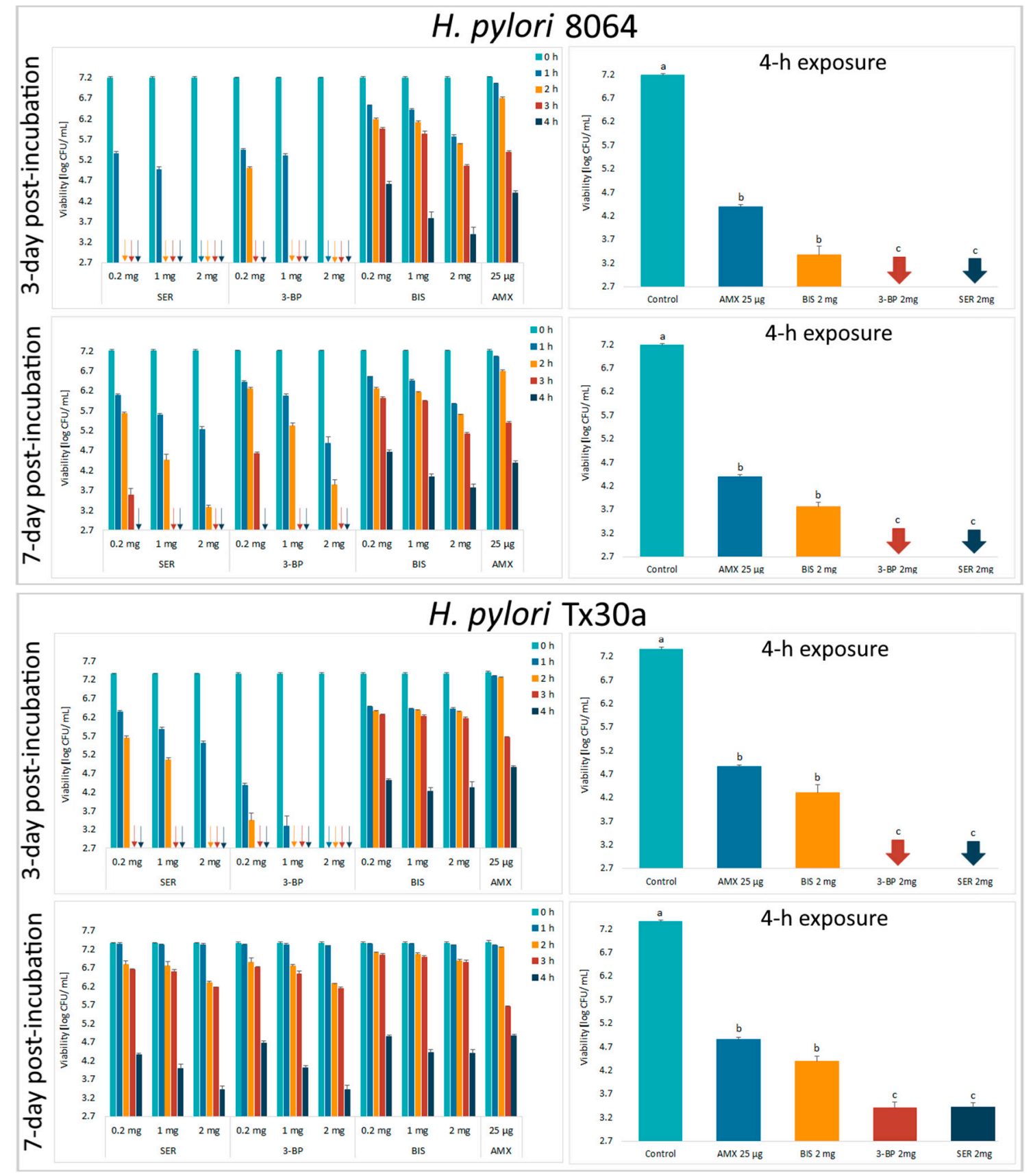

Figure 4. Viability of lawn biofilm of H. pylori 8064 and Tx30a strains after treatment for $1 \mathrm{~h}, 2 \mathrm{~h}$, $3 \mathrm{~h}$, and $4 \mathrm{~h}$ with BC carriers chemisorbed with bismuth subsalicylate (BIS); 3-bromopyruvate (3-BP), sertraline (SER), and amoxicillin (AMX). The colony forming units (CFUs) counting was performed after 3 or 7 days of culturing after exposure to these antimicrobials (the post-treatment period). The arrows indicate values below the detection threshold $\left(500 \mathrm{CFU} / \mathrm{mL}, \log _{10}=2.7\right)$. Columns with the same subscript letters $(a, b, c)$ are not significantly different from each other $(p>0.05)$. The presented results are the average of three independent biological tests $(n=3)$. The results of comparing the statistical significance of all tested samples are presented in the Figure S5. 

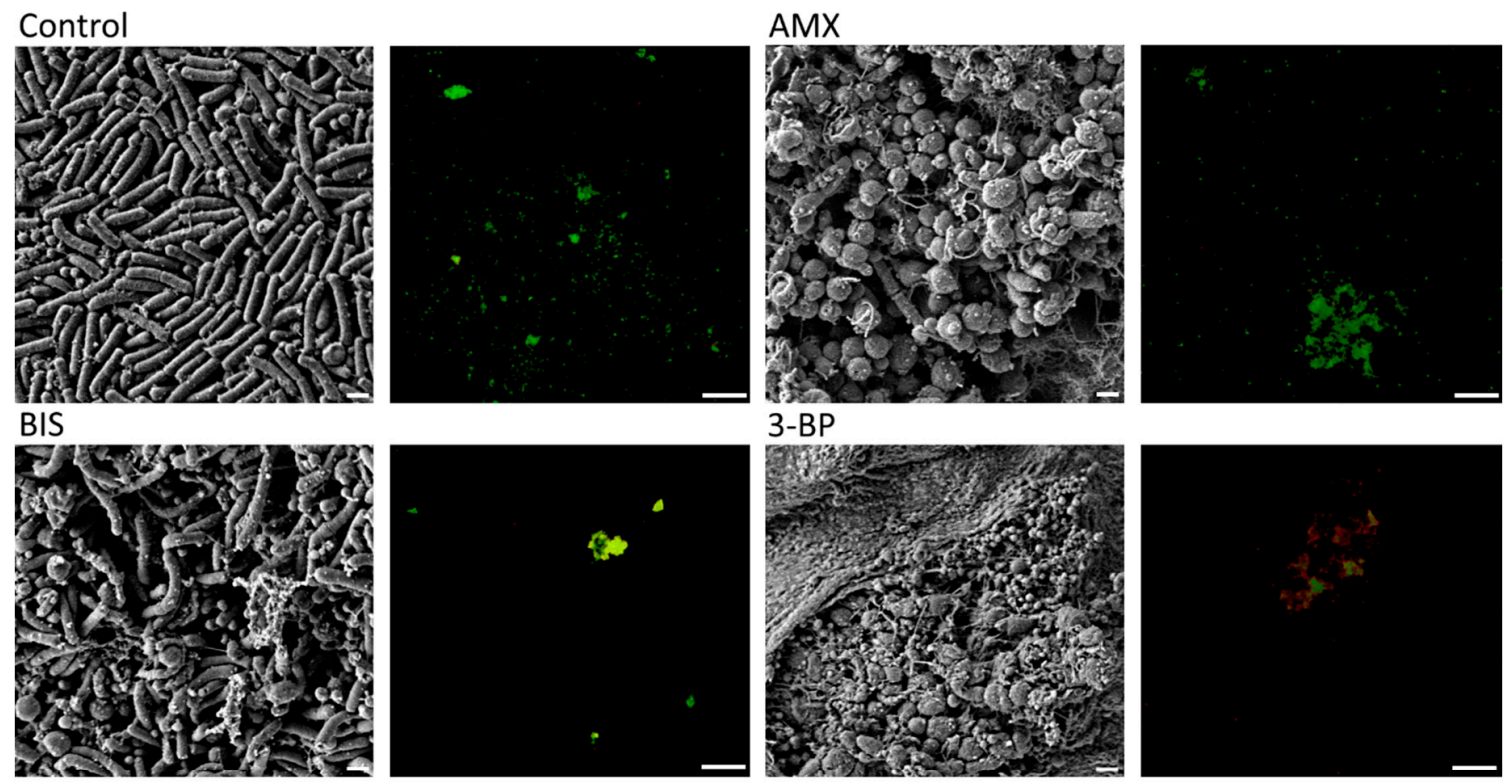

3-BP
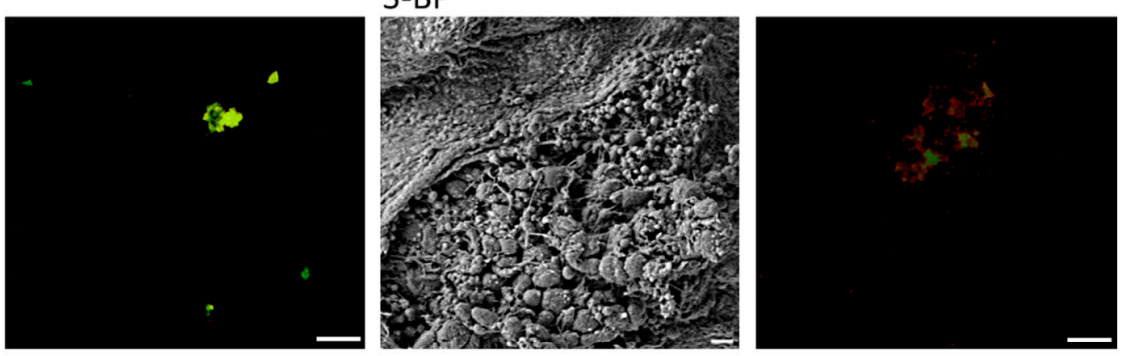

SER
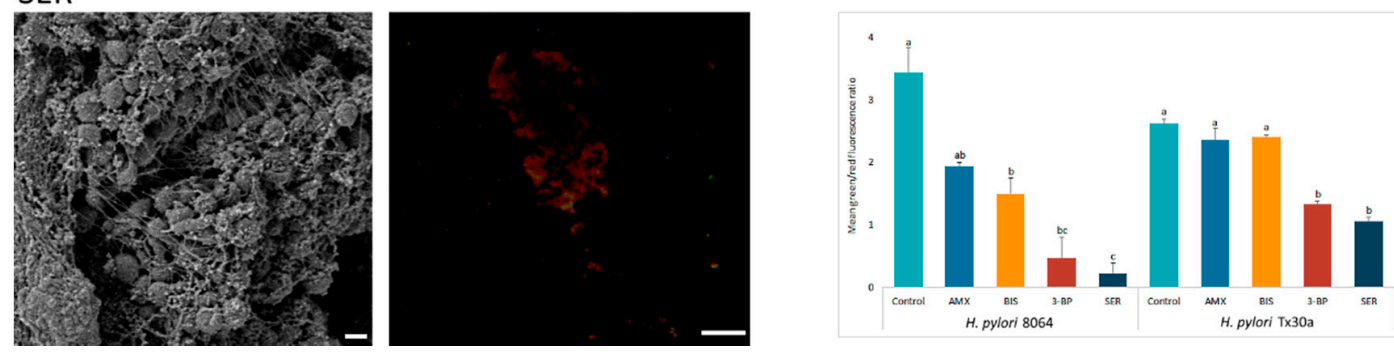

Figure 5. Representative scanning electron and fluorescence microscopy images showing an antibacterial activity of tested compounds (bismuth subsalicylate (BIS), 3-bromopyruvate (3-BP), sertraline (SER), and amoxicillin (AMX)) released from BC carriers after 4-h exposure against 3 day-old, lawn biofilm H. pylori cells. The small spherical structures (50-300 nm) are outer membrane vesicles (OMVs) secreted by bacteria. Green dye (SYTO 9) indicates live cells, while red (propidium iodide) indicates dead cells. The graph shows the ratio of mean green/red fluorescence of lawn biofilm H. pylori cells treated for $4 \mathrm{~h}$ with the tested substances. Columns with the same subscript letters (a, b, c) are not significantly different from each other $(p>0.05)$, counted separately for each strain. The presented results are the average of three independent biological tests $(n=3)$. Scale bar for SEM and fluorescence microscopy is

$2 \mu \mathrm{m}$ and $20 \mu \mathrm{m}$, respectively.

\section{Discussion}

The conception of research presented in this article is based on a scientific re-perception approach [43], developed systematically by our team, especially with regard to bacterial cellulose [32-34]. Re-perception relies basically on application of specific material or device in new environment to obtain favorable and often unexpected outcomes. An example of re-perception approach is use of BC as a carrier of microorganisms [44] or as a local drug-delivery carrier [45], with the second being applied in this work. There is a bulk of evidence showing that use of local drug-delivery systems (liposomes, microspheres, nanoparticles, or polymeric carriers) is an effective and safe type of antimicrobial therapies, which is of particular importance in combating infections caused by multidrug-resistant pathogens [24-26] and may also find a broad application in the treatment of H. pylori infections.

Substances that may be helpful in fighting $H$. pylori infections are 3-BP and SER. In previous studies, our research group showed an antimicrobial activity and synergistic/additive interactions with antibiotics of both these compounds against planktonic $H$. pylori forms [22,23]. Even if the systemic use of 3-BP or SER in the treatment of $H$. pylori is possible [24,25], methods contributing to the reduction/elimination of negative effects associated with the $H$. pylori eradication are an important 
stream of future research [26]. Therefore, our aim was to couple 3-BP and SER with BC carriers to analyze an in vitro potential of this local drug-delivery system to be applied as a counter-measure against $H$. pylori biofilms.

In the first line of our investigation we checked whether analyzed SER or 3-BP alone (non-coupled with a BC carrier) displayed the desired antibacterial activity and compared received results with values obtained for BIS and AMX, both of which are substances of the clinical use (Table 1). It occurred that all tested compounds were able to inhibit or kill H. pylori. Whereas AMX had the highest activity $(\mathrm{MIC}=0.06-0.12 \mu \mathrm{g} / \mathrm{mL}), 3-\mathrm{BP}$ displayed unquestionably the lowest activity (MIC $=128 \mu \mathrm{g} / \mathrm{mL}$ ). Despite unfavorable initial results obtained for 3-BP, we decided to include this substance in further stages of experiment taking into account fact that local drug-delivery carriers allow to provide high concentrations of compounds into selected area.

Therefore, next we produced BC carriers and characterized their properties. The whole batch of $\mathrm{BC}$ was produced in the single cultivation time interval and cleansed using alkaline lysis in a single container, thus allowing us to obtain carriers of exact/almost exact features. Thanks to this approach, we obtained BC carriers of desired shape, porosity, and other parameters (Figure 2), comparable to these presented in our earlier work [35]. Moreover, we showed that BC was not digested and did not alter its structure in the highly acidic environment resembling conditions in stomach (Supplementary Figure S1). The porosity of BC presented in Figure 2, is a BC key parameter with regard to an ability of this biomaterial to absorb fluids. Therefore, the immersion of BC carriers with SER or 3-BP resulted in the chemisorption of these compounds within cellulose matrix as it was proven by a spectroscopy.

The results of a preliminary, modified disk-diffusion test confirmed that analyzed compounds were chemisorbed within $\mathrm{BC}$ and also shown their effective release resulted in formation of growth inhibition zones of H. pylori (Figure 3). Results presented in Figure 3, concerning comparison of 3-BP and BIS activity, stay in contrast to these obtained by means of the standard microplate assay (Table 1). It explicitly highlights not only dependence between results obtained and the type of test applied, but also the obvious need of using various tests to fully understand phenomena related with an assessment of microbial sensitivity to drugs. Also the chemical nature of the substance correlates with its antimicrobial activity [46]. 3-BP is a low-molecular weight compound ( $166 \mathrm{~g} / \mathrm{mol})$, while molecular weight of bismuth subsalicylate (BIS) is more than two times higher $(361 \mathrm{~g} / \mathrm{mol})$. A positive correlation between low-molecular weight of antimicrobials and their ability to penetrate the biofilm matrix has been already demonstrated by other research teams $[47,48]$. Therefore, it can be also assumed that low-weight 3BP would display significantly higher penetration through agar (a disk-diffusion assay) and biofilm matrix (an antimicrobial assay against lawn biofilms) compared to BIS.

Following this idea, we performed an additional, self-developed experimental setting [35,37], in which active compounds released from a BC carrier need to penetrate through liquid microbiological medium and then through 3 day-old, lawn biofilm H. pylori cells (Figure 1). It is worth noting that bacterial cells tested in the current experiments were adhered to the agar surface and immersed in the nutrient medium [38,39], while an alternative model focuses on biofilms and cell aggregates formed at the air-liquid surface [49]. Such procedure may affect the different physiology of H. pylori cells, while it guarantees obtaining high cell biomass, which is difficult to obtain for H. pylori using classical methods. The porosity of surface (enabled in the experimental setting by application of agar-based medium) is a known factor increasing adherence of settled communities of microbes [50] and it allows to obtain more repeatable results than in case when smooth polystyrene and polypropylene surfaces are used for in vitro testing [51]. The proper surface porosity correlates with a higher adherence of cells, which in turn decreases the effect of aggressive pipette-based washing, i.e., the random de-attachment of large amounts of biofilm and/or multicellular aggregates [52]. Therefore, the results obtained in the aforementioned experimental setting (with all limitations relevant to in vitro analyses) may serve as first and prerequisite proof of the concept, which could be developed later on in animal and clinical studies. 
Results presented in Figure 4 and Figure S5 revealed a direct time-dependent and dose-dependent antibacterial effect of these compounds against lawn H. pylori biofilms. For both strains, a growth inhibition effect was significantly higher when an amount of grown colonies was read after three days of incubation than after a one week of culture (the post-treatment period). The reason of this phenomenon is unknown, but it seems that this mechanism was associated with an ability of both 3-BP and SER to reduce metabolism and intracellular ATP level [19-21]. This difference was not seen in bacteria treated with BIS or AMX, although there are studies showing an ability of BIS to disrupt H. pylori metabolism [53-55]. It is possible that SER, 3-BP and BIS affect the metabolism of these bacteria, but may interfere with various metabolic pathways.

The impact of 3-BP and SER has been extended to assess morphological changes in H. pylori, a process for which an involvement in antibiotic tolerance is suggested [56,57]. Bacteria treated with these substances underwent morphological transition to spherical cells (Figures 3 and 5). However, an analysis using fluorescence microscopy showed that the morphological transformation was not protective, because an exposure to these compounds was accompanied by a significant reduction in green fluorescence (Figure 5). The antibacterial nature of 3-BP and SER, as well as the lack of protective function of coccoid forms, are consistent with previous observations of our research group when testing 3-BP and SER against planktonic H. pylori forms [22,23]. It is worth noting that $H$. pylori cells treated with BIS or AMX maintained a high level of green fluorescence (Figure 5). This phenomenon seems to be particularly interesting in the case of AMX, because this antibiotic had a very high bactericidal activity against planktonic forms (a microdilution method, MIC $=0.06-0.12 \mu \mathrm{g} / \mathrm{mL}$ ) and freshly seeded cells settled on the agar (growth inhibition zones produced by $25 \mu \mathrm{g} /$ disk being $\sim 60 \mathrm{~mm}$ ), while significantly lower in relation to 3 day-old, lawn $H$. pylori biofilms (reduction of CFU/mL after a 4 -h incubation was $<3$ logs). A high level of green fluorescence suggests that the observed decrease in $\mathrm{CFU} / \mathrm{mL}$ is rather associated with the loss of culturability in the process of transformation into coccoid forms than the reduction of viability [57]. Our observations are consistent with the reports of others indicating a low bactericidal activity of AMX against biofilm $H$. pylori forms $[58,59]$.

The SEM observation of $H$. pylori cells treated with 3-BP, SER, BIS, or AMX, in addition to morphological transformation, also revealed a presence of a high amount of OMVs. These structures were produced in a significantly higher amount compared to the control samples and were very often larger than in non-treated ones (Figure 5). Proteomic studies of H. pylori OMVs have shown that the size of these structures determines their content and protein composition, which in turn may translate into their functions $[60,61]$. The source of OMVs and an involvement of these structures in antibiotic tolerance of $H$. pylori exposed to antimicrobial substances is another interesting direction of research. We suggest that the presence of numerous OMVs in H. pylori biofilm may determine the low sensitivity of this bacterium to AMX and BIS. The OMVs produced by $H$. pylori possess numerous proteins $[60,61]$ and extracellular DNA (eDNA) particles $[62,63]$, both anchored to the surface of these organelles. The OMVs-dependent tolerance of biofilm H. pylori forms to AMX and BIS could be associated with the presence of beta-lactamases capable of breaking down AMX [61] or eDNA-related chelation of metal ions (including BIS) [64,65]. The suggested mechanism, however, should be experimentally verified.

\section{Conclusions}

In conclusion, the data presented in this article show that SER and 3-BP may be useful in the treatment of H. pylori. Additionally, coupling of these substances with BC carriers may be a promising approach directed to more accurate and efficient treatment of this pathogen. This trend will have to be verified in future in vivo studies. 
Supplementary Materials: The following are available online at http://www.mdpi.com/1422-0067/21/24/9507/s1, Figure S1. Bacterial cellulose incubated in low $\mathrm{pH}$ does not alter its structure. Figure S2. Time-dependent release of 3-bromopyruvate (3-BP) from bacterial cellulose (BC) disks. Figure S3. Time-dependent release of sertraline (SER) from bacterial cellulose (BC) disks. Figure S4. Activity of tested compounds released from paper disks against $H$. pylori 8064 and Tx30a strains measured by a modified disk-diffusion method. Figure S5. Checkerboards showing statistically significant differences between the viability of lawn biofilm cells of $H$. pylori Tx30a and 8064 strains exposed to BC carriers chemisorbed amoxicillin (AMX), bismuth subsalicylate (BIS), sertraline (SER), and 3-bromopyruvate (3-BP) over time. The red and white fields represent a statistically significant $(p<0.05)$ and not significant $(p>0.05)$ differences, respectively (K-W test with a post-hoc Dunn's analysis). Graphical presentation of the results made on the basis of Tripathy et al. (2020) [66].

Author Contributions: P.K. and A.J. provided the concept of manuscript; P.K. validated research methodology; P.K. performed antimicrobial tests; P.K. carried out the fluorescence microscopy; P.M. carried out the scanning electron microscopy; K.F. determined physicochemical properties of biocellulose disks; J.C. prepared and purified biocellulose disks; A.O. analyzed the release of sertraline from biocellulose disks; M.D. analyzed the release of sertraline and 3-BP from biocellulose disks; P.K. analyzed obtained results; P.K. reviewed and collected literature; P.K. prepared the draft and final version of manuscript; P.K. prepared graphics; P.K., A.J., O.A. and G.G. critically reviewed the manuscript; P.K., A.J. and G.G. obtained funds for publishing the article; G.G. supervised the project. All authors have read and agreed to the published version of the manuscript.

Funding: The study was supported by Wroclaw Medical University grant No: SUB.A130.19.021 and ST.D230.18.008. The funders had no role in study design, data collection and analysis, decision to publish, or preparation of the manuscript.

Conflicts of Interest: The authors declare no conflict of interest.

\section{References}

1. Huang, Y.; Wang, Q.-L.; Cheng, D.-D.; Xu, W.-T.; Lu, N.-H. Adhesion and Invasion of Gastric Mucosa Epithelial Cells by Helicobacter pylori. Front. Cell. Infect. Microbiol. 2016, 6, 159. [CrossRef] [PubMed]

2. Johnson, K.S.; Ottemann, K.M. Colonization, Localization, and Inflammation: The Roles of H. pylori Chemotaxis In Vivo. Curr. Opin. Microbiol. 2018, 41, 51-57. [CrossRef] [PubMed]

3. Ansari, S.; Yamaoka, Y. Helicobacter pylori Virulence Factors Exploiting Gastric Colonization and Its Pathogenicity. Toxins (Basel) 2019, 11, 677. [CrossRef] [PubMed]

4. Malfertheiner, P.; Megraud, F.; O’Morain, C.A.; Gisbert, J.P.; Kuipers, E.J.; Axon, A.T.; Bazzoli, F.; Gasbarrini, A.; Atherton, J.; Graham, D.Y.; et al. Management of Helicobacter pylori Infection-The Maastricht V/Florence Consensus Report. Gut 2017, 66, 6-30. [CrossRef]

5. Boyanova, L.; Hadzhiyski, P.; Kandilarov, N.; Markovska, R.; Mitov, I. Multidrug Resistance in Helicobacter pylori: Current State and Future Directions. Expert Rev. Clin. Pharmacol. 2019, 12, 909-915. [CrossRef]

6. Debraekeleer, A.; Remaut, H. Future Perspective for Potential Helicobacter pylori Eradication Therapies. Future Microbiol. 2018, 13, 671-687. [CrossRef]

7. Tacconelli, E.; Carrara, E.; Savoldi, A.; Harbarth, S.; Mendelson, M.; Monnet, D.L.; Pulcini, C.; Kahlmeter, G.; Kluytmans, J.; Carmeli, Y.; et al. Discovery, Research, and Development of New Antibiotics: The WHO Priority List of Antibiotic-Resistant Bacteria and Tuberculosis. Lancet Infect. Dis. 2018, 18, 318-327. [CrossRef]

8. Fallone, C.A.; Moss, S.F.; Malfertheiner, P. Reconciliation of Recent Helicobacter pylori Treatment Guidelines in a Time of Increasing Resistance to Antibiotics. Gastroenterology 2019, 157, 44-53. [CrossRef]

9. Tsay, F.W.; Wu, D.C.; Yu, H.C.; Kao, S.S.; Lin, K.H.; Cheng, J.S.; Wang, H.M.; Chen, W.C.; Sun, W.C.; Tsai, K.W.; et al. A Randomized Controlled Trial Shows that both 14-Day Hybrid and Bismuth Quadruple Therapies Cure Most Patients with Helicobacter pylori Infection in Populations with Moderate Antibiotic Resistance. Antimicrob. Agents Chemother. 2017, 61, e00140-17. [CrossRef]

10. Liou, J.M.; Fang, Y.J.; Chen, C.C.; Bair, M.J.; Chang, C.Y.; Lee, Y.C.; Chen, M.J.; Chen, C.C.; Tseng, C.H.; Hsu, Y.C.; et al. Concomitant, Bismuth Quadruple, and 14-day Triple Therapy in the First-Line Treatment of Helicobacter pylori: A Multicentre, Open-Label, Randomised Trial. Lancet 2016, 388, 2355-2365. [CrossRef]

11. Yang, X.; Wang, J.X.; Han, S.X.; Gao, C.P. High Dose Dual Therapy versus Bismuth Quadruple Therapy for Helicobacter pylori Eradication Treatment: A Systematic Review and Meta-Analysis. Medicine 2019, 98, e14396. [CrossRef] [PubMed] 
12. Hsu, P.-I.; Pan, C.-Y.; Kao, J.Y.; Tsay, F.-W.; Peng, N.-J.; Kao, S.-S.; Wang, H.-M.; Tsai, T.-J.; Wu, D.-C.; Chen, C.-L.; et al. Helicobacter pylori Eradication with Bismuth Quadruple Therapy Leads to Dysbiosis of Gut Microbiota with an Increased Relative Abundance of Proteobacteria and Decreased Relative Abundances of Bacteroidetes and Actinobacteria. Helicobacter 2018, 23, e12498. [CrossRef] [PubMed]

13. Yap, T.W.C.; Gan, H.M.; Lee, Y.P.; Leow, A.H.R.; Azmi, A.N.; Francois, F.; Perez-Perez, G.I.; Loke, M.F.; Goh, K.L.; Vadivelu, J. Helicobacter pylori Eradication Causes Perturbation of the Human Gut Microbiome in Young Adults. PLoS ONE 2016, 11, e0151893. [CrossRef] [PubMed]

14. Chen, L.; Xu, W.; Lee, A.; He, J.; Huang, B.; Zheng, W.; Su, T.; Lai, S.; Long, Y.; Chu, H.; et al. The Impact of Helicobacter pylori Infection, Eradication Therapy and Probiotic Supplementation on Gut Microenvironment Homeostasis: An Open-Label, Randomized Clinical Trial. EBioMedicine 2018, 35, 87-96. [CrossRef] [PubMed]

15. Olekhnovich, E.I.; Manolov, A.I.; Samoilov, A.E.; Prianichnikov, N.A.; Malakhova, M.V.; Tyakht, A.V.; Pavlenko, A.V.; Babenko, V.V.; Larin, A.K.; Kovarsky, B.A.; et al. Shifts in the Human Gut Microbiota Structure Caused by Quadruple Helicobacter pylori Eradication Therapy. Front. Microbiol. 2019, 10, 1902. [CrossRef] [PubMed]

16. Graham, D.Y.; Lee, S.Y. How to Effectively Use Bismuth Quadruple Therapy: The Good, the Bad, and the Ugly. Gastroenterol. Clin. N. Am. 2015, 44, 537-563. [CrossRef] [PubMed]

17. Xin, Q.; Yuan, M.; Li, H.; Song, X.; Lu, J.; Jing, T. In Vitro and In Vivo Effects of 3-Bromopyruvate against Echinococcus metacestodes. Vet. Res. 2019, 50, 96. [CrossRef]

18. Milanes, J.E.; Suryadi, J.; Abendroth, J.; Van Voorhis, W.C.; Barrett, K.F.; Dranow, D.M.; Phan, I.Q.; Patrick, S.L.; Rozema, S.D.; Khalifa, M.M.; et al. Enzymatic and Structural Characterization of the Naegleria fowleri Glucokinase. Antimicrob. Agents Chemother. 2019, 63, e02410-18. [CrossRef]

19. Kumar, A.; Boradia, V.M.; Thakare, R.; Singh, A.K.; Gani, Z.; Das, S.; Patidar, A.; Dasgupta, A.; Chopra, S.; Raje, M.; et al. Repurposing Ethyl Bromopyruvate as a Broad-Spectrum Antibacterial. J. Antimicrob. Chemother. 2019, 74, 912-920. [CrossRef]

20. Ferreira, D.D.; Mesquita, J.T.; da Costa Silva, T.A.; Romanelli, M.M.; da Gama Jaen Batista, D.; da Silva, C.F.; da Gama, A.N.S.; Neves, B.J.; Melo-Filho, C.C.; de Soeiro, M.C.; et al. Efficacy of Sertraline Against Trypanosoma cruzi: An In Vitro and In Silico Study. J. Venom. Anim. Toxins Incl. Trop. Dis. 2018, 24, 30. [CrossRef]

21. Lima, M.L.; Abengózar, M.A.; Nácher-Vázquez, M.; Martínez-Alcázar, M.P.; Barbas, C.; Tempone, A.G.; López-Gonzálvez, Á.; Rivas, L. Molecular Basis of the Leishmanicidal Activity of the Antidepressant Sertraline as a Drug Repurposing Candidate. Antimicrob. Agents Chemother. 2018, 62, e01928-18. [CrossRef] [PubMed]

22. Krzyżek, P.; Franiczek, R.; Krzyżanowska, B.; Łaczmański, Ł.; Migdał, P.; Gościniak, G. In Vitro Activity of 3-Bromopyruvate, an Anti-Cancer Compound, Against Antibiotic-Susceptible and Antibiotic-Resistant Helicobacter pylori Strains. Cancers (Basel) 2019, 11, 229. [CrossRef] [PubMed]

23. Krzyżek, P.; Franiczek, R.; Krzyżanowska, B.; Łaczmański, Ł.; Migdał, P.; Gościniak, G. In Vitro Activity of Sertraline, an Antidepressant, Against Antibiotic-Susceptible and Antibiotic-Resistant Helicobacter pylori Strains. Pathogens 2019, 8, 228. [CrossRef] [PubMed]

24. Vali, M.; Liapi, E.; Kowalski, J.; Hong, K.; Khwaja, A.; Torbenson, M.S.; Georgiades, C.; Geschwind, J.-F.H. Intraarterial Therapy with a New Potent Inhibitor of Tumor Metabolism (3-Bromopyruvate): Identification of Therapeutic Dose and Method of Injection in an Animal Model of Liver Cancer. J. Vasc. Interv. Radiol. 2007, 18, 95-101. [CrossRef]

25. Mandrioli, R.; Mercolini, L.; Raggi, M.A. Evaluation of the Pharmacokinetics, Safety and Clinical Efficacy of Sertraline Used to Treat Social Anxiety. Expert Opin. Drug Metab. Toxicol. 2013, 9, 1495-1505. [CrossRef]

26. Canaparo, R.; Foglietta, F.; Giuntini, F.; Della Pepa, C.; Dosio, F.; Serpe, L. Recent Developments in Antibacterial Therapy: Focus on Stimuli-Responsive Drug-Delivery Systems and Therapeutic Nanoparticles. Molecules 2019, 24, 1991. [CrossRef]

27. Tiwari, G.; Tiwari, R.; Bannerjee, S.; Bhati, L.; Pandey, S.; Pandey, P.; Sriwastawa, B. Drug Delivery Systems: An Updated Review. Int. J. Pharm. Investig. 2012, 2, 11. [CrossRef] 
28. Van Giau, V.; An, S.S.A.; Hulme, J. Recent Advances in the Treatment of Pathogenic Infections using Antibiotics and Nano-Drug Delivery Vehicles. Drug Des. Devel. Ther. 2019, 13, 327-343. [CrossRef]

29. Fijałkowski, K.; Żywicka, A.; Drozd, R.; Junka, A.F.; Peitler, D.; Kordas, M.; Konopacki, M.; Szymczyk, P.; El Fray, M.; Rakoczy, R. Increased Yield and Selected Properties of Bacterial Cellulose Exposed to Different Modes of a Rotating Magnetic Field. Eng. Life Sci. 2016, 16, 483-493. [CrossRef]

30. Champ, M. Carbohydrate Digestion in Monogastric Animals. Reprod. Nutr. Dev. 1985, 25, 819-842. [CrossRef]

31. Żywicka, A.; Fijałkowski, K.; Junka, A.F.; Grzesiak, J.; El Fray, M. Modification of Bacterial Cellulose with Quaternary Ammonium Compounds Based on Fatty Acids and Amino Acids and the Effect on Antimicrobial Activity. Biomacromolecules 2018, 19, 1528-1538. [CrossRef] [PubMed]

32. Junka, A.; Bartoszewicz, M.; Dziadas, M.; Szymczyk, P.; Dydak, K.; Żywicka, A.; Owczarek, A.; Bil-Lula, I.; Czajkowska, J.; Fijałkowski, K. Application of Bacterial Cellulose Experimental Dressings Saturated with Gentamycin for Management of Bone Biofilm In Vitro and Ex Vivo. J. Biomed. Mater. Res. Part. B Appl. Biomater. 2020, 108, 30-37. [CrossRef] [PubMed]

33. Junka, A.; Żywicka, A.; Chodaczek, G.; Dziadas, M.; Czajkowska, J.; Duda-Madej, A.; Bartoszewicz, M.; Mikołajewicz, K.; Krasowski, G.; Szymczyk, P.; et al. Potential of Biocellulose Carrier Impregnated with Essential Oils to Fight Against Biofilms Formed on Hydroxyapatite. Sci. Rep. 2019, 9, 1256. [CrossRef] [PubMed]

34. Dydak, K.; Junka, A.; Szymczyk, P.; Chodaczek, G.; Toporkiewicz, M.; Fijałkowski, K.; Dudek, B.; Bartoszewicz, M. Development and Biological Evaluation of Ti6Al7Nb Scaffold Implants Coated with Gentamycin-Saturated Bacterial Cellulose Biomaterial. PLoS ONE 2018, 13, e0205205. [CrossRef] [PubMed]

35. Krasowski, G.; Wicher-Dudek, R.; Paleczny, J.; Bil-Lula, I.; Fijałkowski, K.; Sedghizadeh, P.P.; Szymczyk, P.; Dudek, B.; Bartoszewicz, M.; Junka, A. Potential of Novel Bacterial Cellulose Dressings Chemisorbed with Antiseptics for the Treatment of Oral Biofilm Infections. Appl. Sci. 2019, 9, 5321. [CrossRef]

36. EUCAST The European Committee on Antimicrobial Susceptibility Testing. Breakpoint Tables for Interpretation of MICs and Zone Diameters, Version 9.0; 2019. Available online: http://www.eucast.org/clinical_breakpoints/ (accessed on 11 November 2019).

37. Junka, A.F.; Żywicka, A.; Szymczyk, P.; Dziadas, M.; Bartoszewicz, M.; Fijałkowski, K. Test (Antibiofilm Dressing's Activity Measurement)—Simple Method for Evaluating Anti-Biofilm Activity of Drug-Saturated Dressings against Wound Pathogens. J. Microbiol. Methods 2017, 143, 6-12. [CrossRef]

38. Lochab, V.; Jones, T.H.; Dusane, D.H.; Peters, C.W.; Stoodley, P.; Wozniak, D.J.; Subramaniam, V.V.; Prakash, S. Ultrastructure Imaging of Pseudomonas aeruginosa Lawn Biofilms and Eradication of the Tobramycin-resistant Variants under In Vitro Electroceutical Treatment. Sci. Rep. 2020, 10, 9879. [CrossRef]

39. Dusane, D.H.; Brooks, J.R.; Sindeldecker, D.; Peters, C.W.; Li, A.; Farrar, N.R.; Diamond, S.M.; Knecht, C.S.; Plaut, R.D.; Delury, C.; et al. Complete Killing of Agar Lawn Biofilms by Systematic Spacing of Antibiotic-Loaded Calcium Sulfate Beads. Materials (Basel) 2019, 12, 4052. [CrossRef]

40. Cooke, A.C.; Nello, A.V.; Ernst, R.K.; Schertzer, J.W. Analysis of Pseudomonas aeruginosa Biofilm Membrane Vesicles Supports Multiple Mechanisms of Biogenesis. PLoS ONE 2019, 14, e0212275. [CrossRef]

41. Zhang, Y.; Wen, Y.; Xiao, Q.; Zheng, W.; Long, G.; Chen, B.; Shu, X.; Jiang, M. Mutations in the Antibiotic Target Genes Related to Clarithromycin, Metronidazole and Levofloxacin Resistance in Helicobacter pylori Strains from Children in China. Infect. Drug Resist. 2020, 13, 311-322. [CrossRef]

42. Lauener, F.N.; Imkamp, F.; Lehours, P.; Buissonnière, A.; Benejat, L.; Zbinden, R.; Keller, P.M.; Wagner, K. Genetic Determinants and Prediction of Antibiotic Resistance Phenotypes in Helicobacter pylori. J. Clin. Med. 2019, 8, 53. [CrossRef] [PubMed]

43. Bloom, H.K. Global Brain: The Evolution of Mass Mind from the Big Bang to the 21st Century; Wiley: Hoboken, NJ, USA, 2000; ISBN 9780471295846.

44. Drozd, R.; Rakoczy, R.; Wasak, A.; Junka, A.; Fijałkowski, K. The Application of Magnetically Modified Bacterial Cellulose for Immobilization of Laccase. Int. J. Biol. Macromol. 2018, 108, 462-470. [CrossRef] [PubMed]

45. Almeida, I.F.; Pereira, T.; Silva, N.H.C.S.; Gomes, F.P.; Silvestre, A.J.D.; Freire, C.S.R.; Sousa Lobo, J.M.; Costa, P.C. Bacterial Cellulose Membranes as Drug Delivery Systems: An In Vivo Skin Compatibility Study. Eur. J. Pharm. Biopharm. 2014, 86, 332-336. [CrossRef] [PubMed] 
46. Justo, J.A.; Bookstaver, P.B. Antibiotic Lock Therapy: Review of Technique and Logistical Challenges. Infect. Drug Resist. 2014, 7, 343-363. [PubMed]

47. Singh, R.; Kumari, A.; Kaur, K.; Sethi, P.; Chakrabarti, A. Relevance of Antifungal Penetration in Biofilm-Associated Resistance of Candida albicans and non-albicans Candida Species. J. Med. Microbiol. 2018, 67, 922-926. [CrossRef] [PubMed]

48. Sankaran, J.; Tan, N.J.H.J.; But, K.P.; Cohen, Y.; Rice, S.A.; Wohland, T. Single Microcolony Diffusion Analysis in Pseudomonas aeruginosa Biofilms. npj Biofilms Microbiomes 2019, 5, 35. [CrossRef]

49. Hathroubi, S.; Zerebinski, J.; Ottemann, K.M. Helicobacter pylori Biofilm Involves a Multigene Stress-Biased Response, Including a Structural Role for Flagella. MBio 2018, 9, e01973-18. [CrossRef]

50. Bordeleau, E.; Mazinani, S.A.; Nguyen, D.; Betancourt, F.; Yan, H. Abrasive Treatment of Microtiter Plates Improves the Reproducibility of Bacterial Biofilm Assays. RSC Adv. 2018, 8, 32434-32439. [CrossRef]

51. Azeredo, J.; Azevedo, N.F.; Briandet, R.; Cerca, N.; Coenye, T.; Costa, A.R.; Desvaux, M.; Di Bonaventura, G.; Hébraud, M.; Jaglic, Z.; et al. Critical Review on Biofilm Methods. Crit. Rev. Microbiol. 2017, 43, 313-351. [CrossRef]

52. Tasse, J.; Cara, A.; Saglio, M.; Villet, R.; Laurent, F. A Steam-Based Method to Investigate Biofilm. Sci. Rep. 2018, 8, 13040. [CrossRef]

53. He, X.; Liao, X.; Li, H.; Xia, W.; Sun, H. Bismuth-Induced Inactivation of Ferric Uptake Regulator from Helicobacter pylori. Inorg. Chem. 2017, 56, 15041-15048. [CrossRef] [PubMed]

54. Guo, Y.; Guan, C.; Wan, H.; Zhang, Z.; Li, H.; Sun, H.; Xia, W. Inactivation of NikR from Helicobacter pylori by a Bismuth Drug. J. Inorg. Biochem. 2019, 196, 110685. [CrossRef] [PubMed]

55. Wang, Y.; Hu, L.; Xu, F.; Quan, Q.; Lai, Y.T.; Xia, W.; Yang, Y.; Chang, Y.Y.; Yang, X.; Chai, Z.; et al. Integrative Approach for the Analysis of the Proteome-Wide Response to Bismuth Drugs in: Helicobacter pylori. Chem. Sci. 2017, 8, 4626-4633. [CrossRef] [PubMed]

56. Sun, Y.; Zhang, J. Helicobacter pylori Recrudescence and Its Influencing Factors. J. Cell. Mol. Med. 2019, 23, 7919-7925. [CrossRef]

57. Krzyżek, P.; Grande, R. Transformation of Helicobacter pylori into Coccoid Forms as a Challenge for Research Determining Activity of Antimicrobial Substances. Pathogens 2020, 9, 184. [CrossRef]

58. Hathroubi, S.; Zerebinski, J.; Clarke, A.; Ottemann, K.M. Helicobacter pylori Biofilm Confers Antibiotic Tolerance in Part via a Protein-Dependent Mechanism. Antibiotics 2020, 9, 355. [CrossRef] [PubMed]

59. Chen, X.; Li, P.; Shen, Y.; Zou, Y.; Yuan, G.; Hu, H. Rhamnolipid-involved Antibiotics Combinations Improve the Eradication of Helicobacter pylori Biofilm In Vitro: A Comparison with Conventional Triple Therapy. Microb. Pathog. 2019, 131, 112-119. [CrossRef]

60. Turner, L.; Bitto, N.J.; Steer, D.L.; Lo, C.; D'Costa, K.; Ramm, G.; Shambrook, M.; Hill, A.F.; Ferrero, R.L.; Kaparakis-Liaskos, M. Helicobacter pylori Outer Membrane Vesicle Size Determines their Mechanisms of Host Cell Entry and Protein Content. Front. Immunol. 2018, 9, 1466. [CrossRef] [PubMed]

61. Zavan, L.; Bitto, N.J.; Johnston, E.L.; Greening, D.W.; Kaparakis-Liaskos, M. Helicobacter pylori Growth Stage Determines the Size, Protein Composition, and Preferential Cargo Packaging of Outer Membrane Vesicles. Proteomics 2019, 19, e1800209. [CrossRef] [PubMed]

62. Grande, R.; Di Giulio, M.; Bessa, L.J.; Di Campli, E.; Baffoni, M.; Guarnieri, S.; Cellini, L. Extracellular DNA in Helicobacter pylori Biofilm: A Backstairs Rumour. J. Appl. Microbiol. 2011, 110, 490-498. [CrossRef]

63. Grande, R.; Di Marcantonio, M.C.; Robuffo, I.; Pompilio, A.; Celia, C.; Di Marzio, L.; Paolino, D.; Codagnone, M.; Muraro, R.; Stoodley, P.; et al. Helicobacter pylori ATCC 43629/NCTC 11639 Outer Membrane Vesicles (OMVs) from Biofilm and Planktonic Phase Associated with Extracellular DNA (eDNA). Front. Microbiol. 2015, 6, 1369. [CrossRef] [PubMed]

64. Mulcahy, H.; Charron-Mazenod, L.; Lewenza, S. Extracellular DNA Chelates Cations and Induces Antibiotic Resistance in Pseudomonas aeruginosa Biofilms. PLoS Pathog. 2008, 4, e1000213. [CrossRef] [PubMed]

65. Lewenza, S.; Johnson, L.; Charron-Mazenod, L.; Hong, M.; Mulcahy-O'Grady, H. Extracellular DNA Controls Expression of Pseudomonas aeruginosa Genes Involved in Nutrient Utilization, Metal Homeostasis, Acid pH Tolerance and Virulence. J. Med. Microbiol. 2020, 69, 895-905. [CrossRef] [PubMed] 
66. Tripathy, K.; Markow, Z.E.; Fishell, A.K.; Sherafati, A.; Burns-Yocum, T.M.; Schroeder, M.L.; Svoboda, A.M.; Eggebrecht, A.T.; Anastasio, M.A.; Schlaggar, B.L.; et al. Decoding Visual Information from High-Density Diffuse Optical Tomography Neuroimaging Data. Neuroimage 2020, 226, 117516. [CrossRef] [PubMed]

Publisher's Note: MDPI stays neutral with regard to jurisdictional claims in published maps and institutional affiliations.

(C) 2020 by the authors. Licensee MDPI, Basel, Switzerland. This article is an open access article distributed under the terms and conditions of the Creative Commons Attribution (CC BY) license (http://creativecommons.org/licenses/by/4.0/). 